\title{
Intramolecular inhibition of activating transcription factor-2 function by its DNA-binding domain
}

\author{
Xiao-Yong Li and Michael R. Green ${ }^{1}$ \\ Howard Hughes Medical Institute, Program in Molecular Medicine, University of Massachusetts Medical Center, Worcester, \\ Massachusetts 01605 USA
}

\begin{abstract}
ATF-2 is a cellular basic region-leucine zipper (bZIP) transcription factor that can mediate diverse transcriptional responses, including activation by the adenovirus E1a protein. ATF-2 contains an activation domain, required for transcriptional activity, but in the absence of an appropriate inducer, full-length ATF-2 is transcriptionally inactive. Here we have investigated the mechanism underlying this regulated inhibition of ATF-2 transcriptional activity. We show that the region of ATF-2 that suppresses the activation region is the bZIP DNA-binding domain and that maximal inhibition requires both the basic region and leucine zipper subdomains. Inhibition is activation domain specific: The ATF-2 bZIP suppresses the ATF-2 and the related E1a activation domains but not acidic- and glutamine-rich activation domains. In vitro protein interaction assays demonstrate that the ATF-2 activation domain and bZIP specifically bind to one another. Finally, we show that bZIP-mediated inhibition can be modulated in a cell-type-specific manner by another sequence element within ATF-2. On the basis of these and other data, we propose that the ATF-2 bZIP and activation domain are engaged in an inhibitory intramolecular interaction and that inducers of ATF-2 disrupt this interaction to activate transcription.
\end{abstract}

[Key Words: ATF-2; transcription activator; bZIP DNA-binding domain; activation domain; cell-type specificity]

Received August 21, 1995; revised version accepted January 24, 1996.

Eukaryotic gene expression is largely controlled at the transcriptional level through regulation of promoter-specific transcription factors. For example, the activity of various transcription factors can be affected by small molecule ligands (e.g., steriod hormone receptors), by phosphorylation, and by interactions with regulatory proteins (for review, see Evans 1988; Martin and Green 1992; Karin and Hunter 1995). An important class of regulatory proteins are viral transcription activators such as adenovirus Ela (for review, see Flint and Shenk 1989, Martin and Green 1992) and herpes simplex virus VP16 (for review, see Thompson and McKnight 1992; O'Hare 1993). These viral proteins do not bind directly to DNA but instead function through interactions with promoter-specific transcription factors that have sequence-specific DNA-binding activity.

A promoter-specific transcription factor that has received considerable attention is activating transcription factor-2 (ATF-2), a member of the ATF/CREB (cAMP responsive element binding) protein family of basic region-leuciné zipper ( $\bar{b} Z$ IP) DNA-binding proteins (Hai et al. 1989; Maekawa et al. 1989). ATF-2 is of particular interest because it can be regulated by several, appar-

${ }^{1}$ Corresponding author. ently diverse inducers. In particular, ATF-2 can mediate transcriptional activation by the 289 -amino-acid adenovirus Ela protein (Liu and Green 1990; Maekawa et al. 1991; Chatton et al. 1993; Liu and Green 1994; Livingstone et al. 1995). In addition, ATF-2 has been implicated as the target for the hepatitis B virus protein $\mathrm{pX}$ (Maguire et al. 1991), the human T-cell leukemia virus type I (HTLV-I) activator Tax (Franklin et al. 1993; Wagner and Green 1993), as well as the retinoblastoma gene product (pRB) (Kim et al. 1992). ATF-2 is also required for viral RNA-induced activation of the human interferon $\beta$ gene, a mechanism that involves interaction with the high mobility group protein [HMGI(Y)] (Du et al. 1993). Finally, in response to extracellular signals ATF-2 has been shown to be regulated by phosphorylation (Abdel-Hafiz et al. 1992b; Gupta et al. 1995; Livingstone et al. 1995; van Dam et al. 1995).

An important aspect of transcription factor activation, is the mechanism that renders the factor inactive in the absence of an inducer. Full-length ATF-2, either in its native form (Georgopoulos et al. 1992; Ivashkiv et al. 1992) or as a GAL4 fusion protein (Liu and Green 1990), is transcriptionally inactive. However, ATF-2 contains an activation domain and when this minimal activation domain is directed to a promoter it is a potent activator 
of transcription (Liu and Green 1994; Livingstone et al. 1995; see below). Thus, the intrinsic activity of the minimal ATF-2 activation domain is suppressed in the context of the full-length protein.

Here, we have performed experiments to understand why in the absence of an inducer full-length ATF- 2 is transcriptionally inactive. We delineate the element in ATF-2 required for inhibition and find, surprisingly, that it is the bZIP DNA-binding domain. We show further that inhibition involves interaction between the bZIP and ATF-2 activation domain. Our results suggest a model in which the ATF-2 bZIP DNA-binding and activation domains are coordinately regulated.

\section{Results}

The ATF-2 activation domain is inhibited by its bZIP DNA-binding domain

The transcriptional activity of ATF- 2 and derivatives was tested in a transient expression assay following fusion to the GAL4(1-147) DNA-binding domain. In this experiment and those presented below, comparable expression of each GAL4 fusion protein was verified by immunobloting (see below; data not shown). Consistent with previous results (Liu and Green 1990; Georgopou- los et al. 1992; Ivashkiv et al. 1992), Figure 1 shows that full-length ATF-2 [GAL4-ATF-2(1-505)] failed to activate transcription, whereas a minimal ATF-2 activation domain [GAL4-ATF-2(N)] was highly active. These results suggested that a sequence within ATF-2 inhibits the intrinsic activity of the activation domain. To identify this inhibitory sequence, we analyzed a series of ATF-2 carboxy-terminal deletion mutants. Figure 1 shows that GAL4-ATF-2(1-415), which lacks the sequence carboxy-terminal to the bZIP DNA-binding domain, was a poor transcriptional activator. Significantly, however, GAL4-ATF-2(1-349), which differs from GAL4-ATF-2(1-415) only by the absence of the bZIP DNA-binding domain, was 200 -fold more active than GAL4-ATF-2(1-415). Further deletion of residues 110349 resulted in a modest (about fourfold) increase in activity. These results indicate that inhibition of the ATF-2 activation domain depends on the bZIP motif. To verify this idea, we fused the bZIP domain directly to the activation domain and found that the resulting protein [GAL4-ATF-2(N,bZIP)] was inactive. Thus, the ATF-2 bZIP is sufficient for inhibition.

The activities and expression levels of the GAL4 ATF-2 fusion proteins were analyzed in COS-1 cells. Figure $2 \mathrm{~A}$ shows that as in HeLa cells, the bZIP strongly

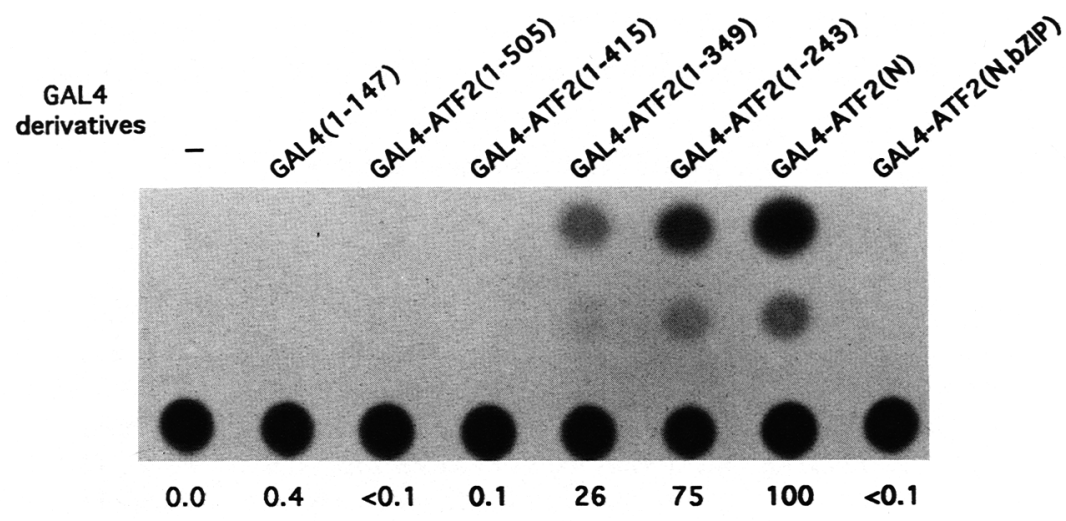

Figure 1. Transcriptional activities of GAL4-ATF-2 deletion derivatives in $\mathrm{HeLa}$ cells. HeLa cells were cotransfected with plasmids expressing the GAL4-ATF-2 fusion proteins, indicated at the top of each lane, the CAT reporter pG5E1bCAT (Lillie and Green 1989), and the internal control plasmid RSV- $\beta$-gal by the calcium-phosphate transfection procedure. Cell extracts were prepared $36 \mathrm{hr}$ post-transfection and assayed for CAT and $\beta$-galactosidase activity. A representative autoradiograph is shown. The CAT activities normalized to that of GAL4-ATF-2(N) are shown at the bottom; variations in CAT activity were $<20 \%$. Diagrams of the GAL4-ATF- $2 \mathrm{fu}$ sion proteins are also indicated.

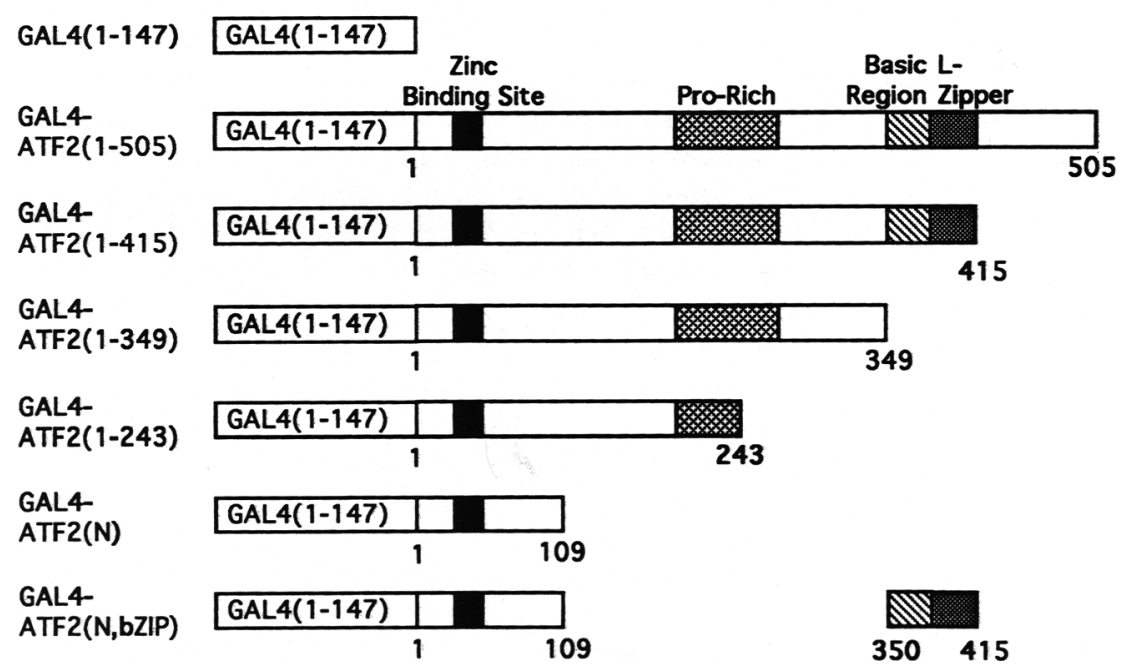


inhibited the ATF-2 activation domain. Immunobloting analysis (Fig. 2B) shows that the differences in transcriptional activities of the GAL4-ATF-2 fusion proteins cannot be explained by variations in their levels of expression.

\section{Efficient inhibition of ATF-2 activation domain requires both the basic region and the leucine zipper subdomains}

The bZIP domain consists of two functionally separable subdomains: the basic region and the leucine zipper (LZ) (Johnson and McKnight 1989). To analyze the role of these subdomains in transcriptional inhibition we tested the activities of carboxy-terminal deletion mutants lacking either the LZ region [GAL4-ATF-2(1-380)] or the entire bZIP domain [GAL4-ATF-2(1-349)]. Figure 3A shows that both fusion proteins were comparably active, indicating that the basic region is not sufficient for inhibition.

To analyze the role of the LZ, we fused it directly to the carboxyl terminus of the activation domain $(\mathrm{N})$ and found that the resulting protein [GAL4-ATF-2(N,LZ)] was significantly more active than that containing the intact bZIP domain [GAL4-ATF-2(N,bZIP)] (Fig. 3B). From these results, we conclude that efficient inhibition requires both the basic region and the LZ.

\section{Ability of heterologous bZIPs to inhibit the ATF-2 activation domain}

Next, we asked whether inhibition was specific to the
ATF-2 bZIP by testing whether the bZIP of CREB, an ATF/CREB family member, the bZIPs of c-Jun and c-Fos, Jun/Fos family members, and the bZIP of C/EBP (CCAAT/enhancer binding protein) a C/EBP family member, could inhibit the ATF-2 activation domain. Each bZIP was fused to the carboxyl terminus of GAL4 ATF-2(1-349). Figure 4 shows that the CREB bZIP inhibited as well as the ATF-2 bZIP domain, and that the c-Jun and C/EBP bZIPs also inhibited but with a slightly lower efficiency. Significantly, the c-Fos bZIP, which cannot homodimerize (see, e.g., O'Shea et al. 1989), was not inhibitory. This result, in conjunction with those of Figure $3 \mathrm{~A}$, indicates that inhibition requires a bZIP that can dimerize.

\section{Inhibition does not involve a $b Z I P-D N A$ interaction}

One possible, but unlikely, explanation for the observed inhibition was that the bZIP domain sequesters the GAL4 fusion protein to irrelevant bZIP DNA-binding sites on genomic DNA. To rule out this possibility, we analyzed a fusion protein containing a CREB bZIP domain mutant, $\mathrm{K} 304 \mathrm{E}$, which is defective in DNA binding (Dwarki et al. 1990). Figure 5 shows that this CREB bZIP mutant inhibited the ATF-2 activation domain as efficiently as the wild-type CREB bZIP. Thus, inhibition of the ATF-2 activation domain does not involve bZIP DNA binding.

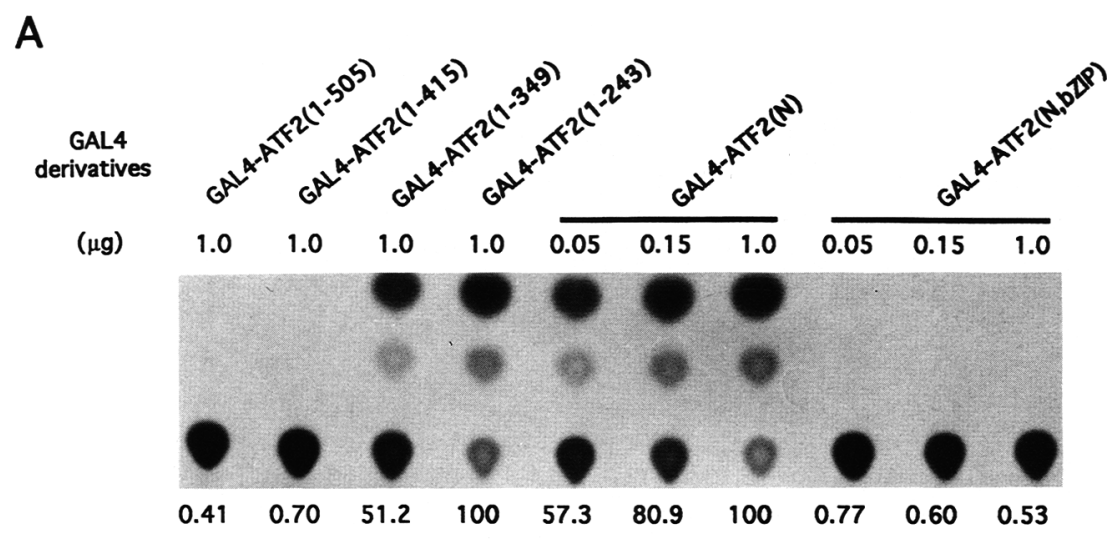

B

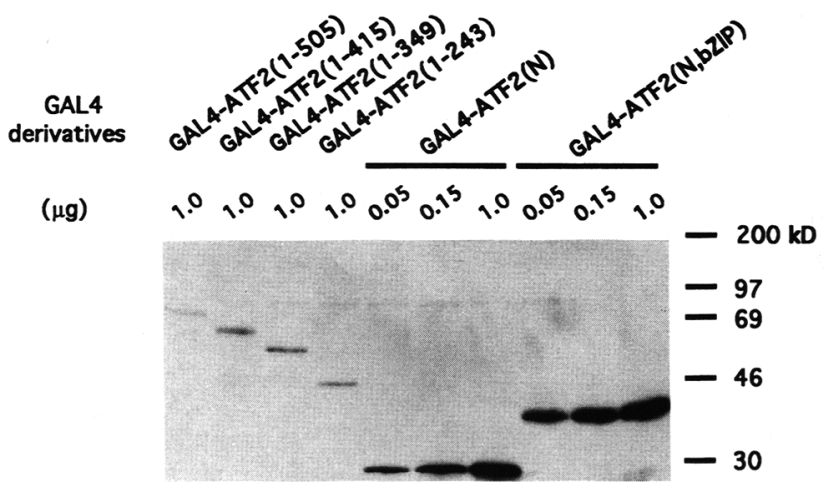

Figure 2. Analysis of GAL4-ATF-2 deletion derivatives in COS- 1 cells. COS- 1 cells were cotransfected with the indicated amount of expression plasmid and $2 \mu \mathrm{g}$ of the CAT reporter pG5E1bCAT (Lillie and Green 1989). (A) CAT assay; (B) Immunoblot analysis. 
A
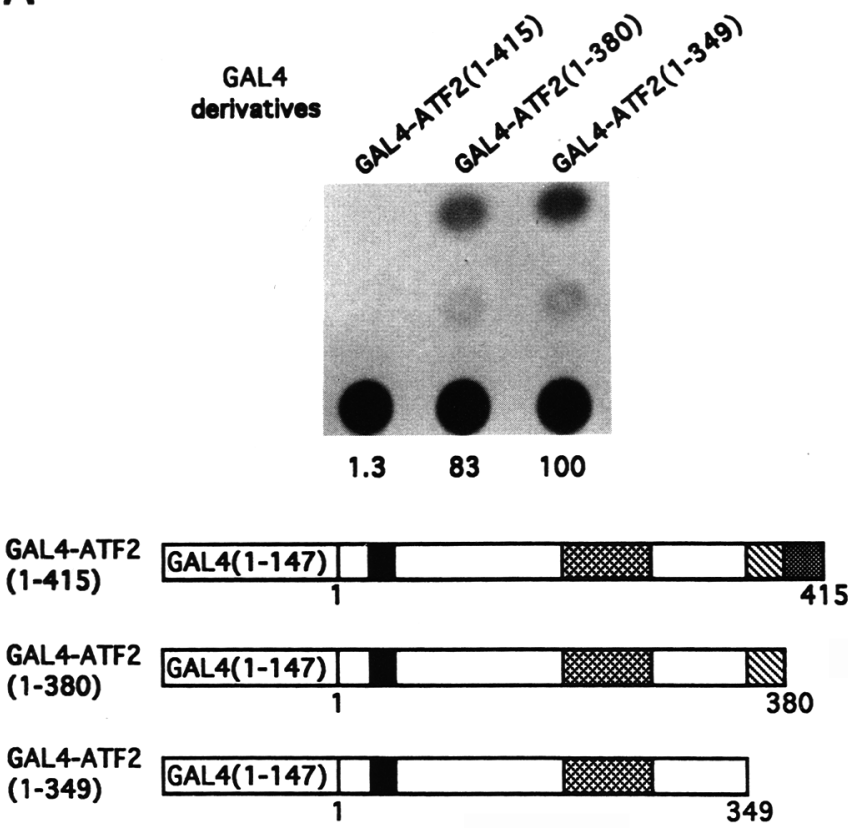

B

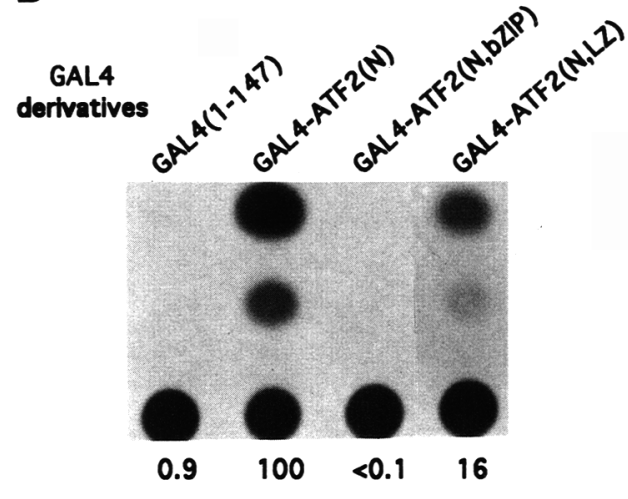

GAL4(1-147) GAL4(1-147)

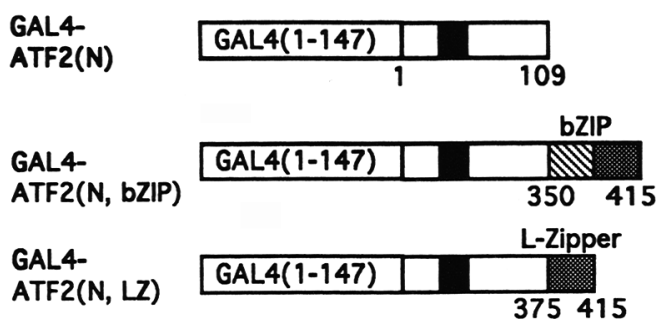

Figure 3. Efficient inhibition of the ATF-2 activation domain requires both the basic region and leucine zipper (see Fig. 1 legend). $|A|$ Analysis of the basic region $(B) ;(B)$ analysis of the leucine zipper (LZ).

\section{Activation domain specificity of bZIP-mediated inhibition}

To determine whether bZIP-mediated inhibition was activation domain specific, we analyzed fusion proteins in which the ATF-2 bZIP was attached to the carboxyl terminus of the acidic VP16 activation domain (Triezenberg et al. 1988) [GAL4-VP16-ATF-2(bZIP)], the glutaminerich activation region A of Sp1 (Courey and Tjian 1988)

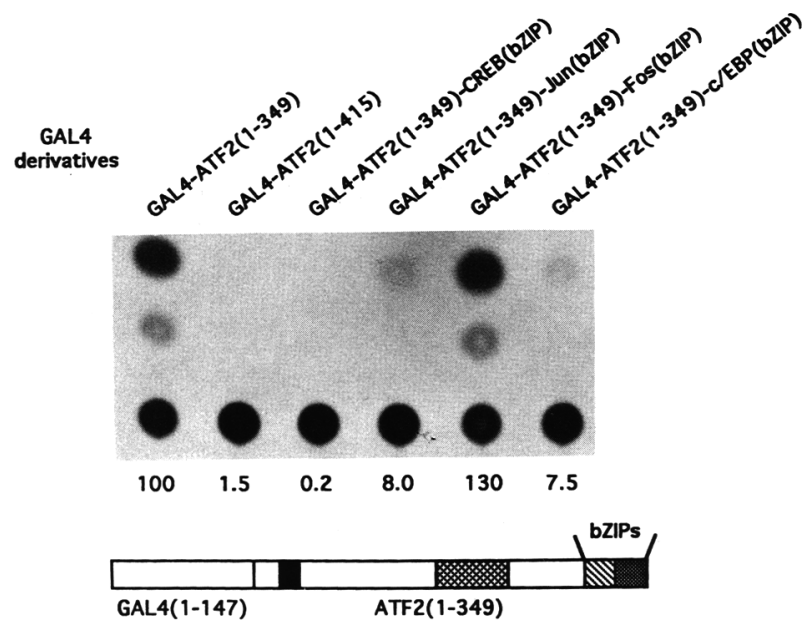

Figure 4. Inhibition of the ATF-2 activation domain by different bZIPs (see Fig. 1 legend).
[GAL4-SP1(Q)-ATF-2(bZIP)], or the zinc-binding activation domain of the adenovirus Ela protein (Lillie and Green 1989) [GAL4-E1a(CR3)-ATF-2(bZIP)]. The activity of each fusion protein was compared with that of its respective counterpart, which lacked the ATF2 bZIP. Figure 6 shows that neither the VP16 activation domain nor the SP1 glutamine-rich activation domain was inhibited by the ATF-2 bZIP, whereas the Ela activation domain was rendered inactive. Immunobloting analysis (Fig. 6A) shows that the differences in transcriptional activities of the GAL4-ATF-2 fusion proteins cannot be explained by variations in their levels of expression. As discussed below, the ATF-2 and Ela activation domains have common structural and functional properties. Therefore, the bZIP domain can inhibit only certain classes of activation domains.

\section{Direct interaction between the ATF-2 activation domain and $b Z I P$}

One possible mechanism for the observed inhibition is a direct, intramolecular interaction between the bZIP and ATF-2 activation domains. To test this idea, we performed an in vitro protein interaction experiment. ATF-2 fragments $1-349$ or $1-109$, which contain the activation domain, were expressed as glutathione $S$-transferase (GST) fusion proteins, immobilized on glutathione-agarose beads (see Fig. 7A) and incubated with bacterially expressed ATF-2 fragment (350-505) containing 

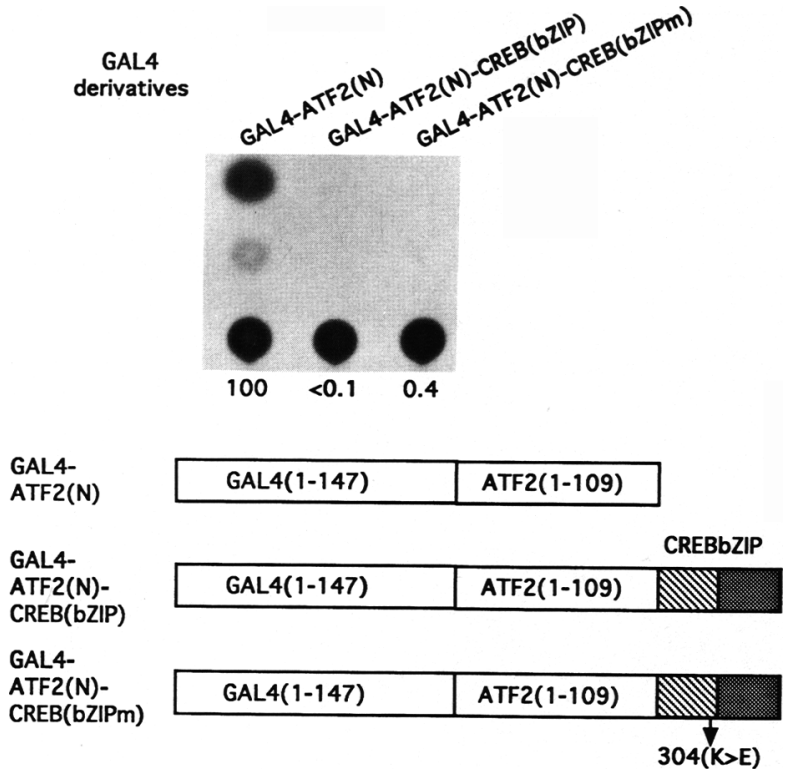

Figure 5. A mutant bZIP defective in DNA binding can inhibit the ATF-2 activation domain (see Fig. 1 for legend). As indicated in the diagram, CREB bZIPm contains a single amino acid substitution (Lys $\rightarrow$ Glu) at position 304 in the bZIP (Dwarki et al. 1990).

the bZIP domain. After extensive washing, retention of ATF-2/350-505) was analyzed by immunoblotting. Figure $7 \mathrm{~B}$ shows that both GST-ATF-2(1-349) and GSTATF-2(1-109) efficiently bound the bZIP-containing fragment, ATF-2(350-505). In contrast, ATF-2(350-505) did not bind to the control GST protein, or to GST-
VP16, which can interact with a variety of other proteins (for review, see Triezenberg 1995). We conclude that the ATF-2 activation domain and the ATF-2 bZIP DNAbinding domain interact specifically with one another.

We also tested the ability of the CREB and c-Fos bZIPs to interact with the ATF-2 activation domain. Figure $7 \mathrm{C}$ shows that the CREB bZIP bound to immobilized GSTATF-2(1-109), whereas the c-Fos bZIP did not. Therefore, there is a direct correlation between the ability of bZIPs to inhibit and interact with the ATF-2 activation domain.

\section{Cell-type specificity of bZIP-mediated inhibition}

Some promoter-specific transcription factors are active only in certain cell types (see, e.g., Baichwal and Tjian 1990). To determine whether bZIP-mediated inhibition was cell-type specific, we analyzed the GAL4-ATF-2 fusion proteins in several other cell lines. The results of Figure 8 show that the relative activities of the various GAL4-ATF-2 fusion proteins in monkey kidney (CV-1), Chinese hamster ovary (CHO), and HeLa cells were very similar. In contrast, in mink lung CCL64 cells, often used in signal transduction studies, the activities of GAL4-ATF-2 or GAL4-ATF-2(1-415), which both contain the bZIP, were comparable to that of GAL4-ATF2(1-349), which lacks the bZIP. Thus, inhibition of the ATF-2 activation domain by the bZIP is cell-type specific.

A specific ATF-2 sequence is responsible for cell-type-specific regulation

The data of Figure 9 show that in CCL64 cells, GAL4-
A
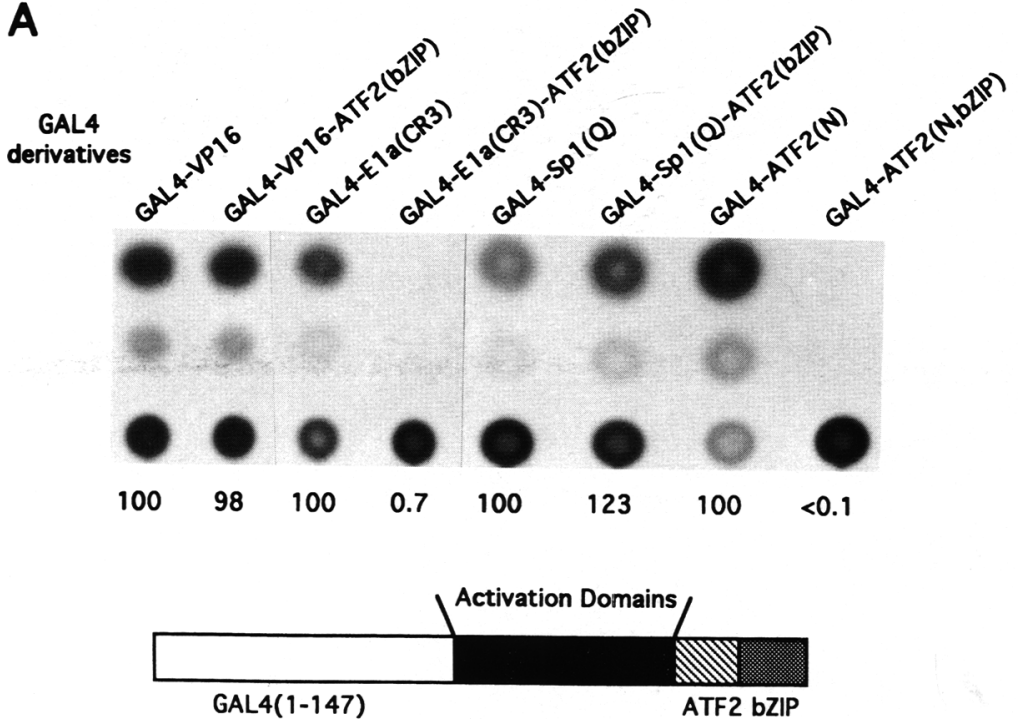

B

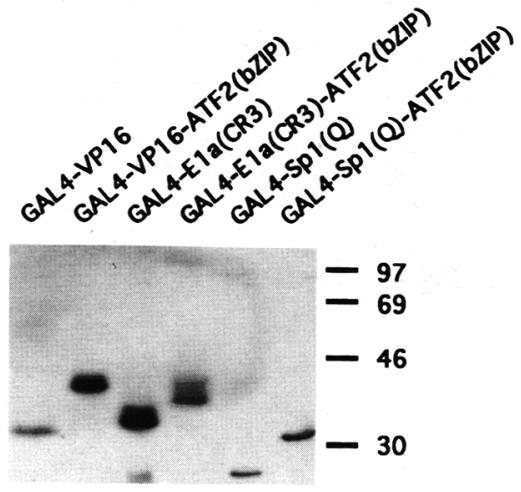

Figure 6. Activation domain specificity of bZIP-mediated inhibition. $(A)$ As in the Fig. 1 legend, except that for the different types of activation domains, the amount of cell extract analyzed was adjusted so that roughly comparable autoradiographic signals were obtained. The activity of the GAL4 fusion protein containing the activation domain alone was arbitrarily assigned as 100 . $(B)$ Immunoblot analysis. COS-1 cells were transfected with $0.5 \mu \mathrm{g}$ of each expression plasmid. 
Figure 7. Direct interaction between the ATF-2 activation domain and bZIP. Glutathione-agarose beads containing immobilized GST, GST-VP16, GST-ATF-2(1$349)$, or GST-ATF-2(1-109) were incubated with bacterially expressed $6 \mathrm{His}-$ ATF-2(350-505), 6His-CREB(bZIP), or 6His-c-Fos(bZIP). After washing, bound His-tagged proteins were detected by immunoblotting with monoclonal T7-Tag antibody (Novagen). (A) Coomassie-blue stained SDS-polyacrylamide gel demonstrating that equal amounts of immobilized fusion proteins were used for the protein-affinity chromatography assays. $(B)$ Immunoblot of 6His-ATF-2(350-505). (C) Immunoblot of 6His-ATF-2(350-505), $6 \mathrm{His}-\mathrm{CREB}(\mathrm{bZIP})$, and $6 \mathrm{His}-\mathrm{c}-\mathrm{Fos}(\mathrm{bZIP})$.

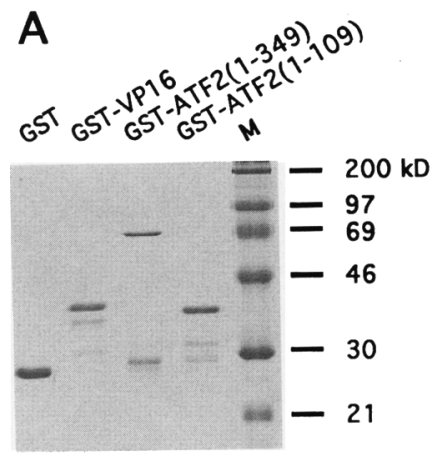

B

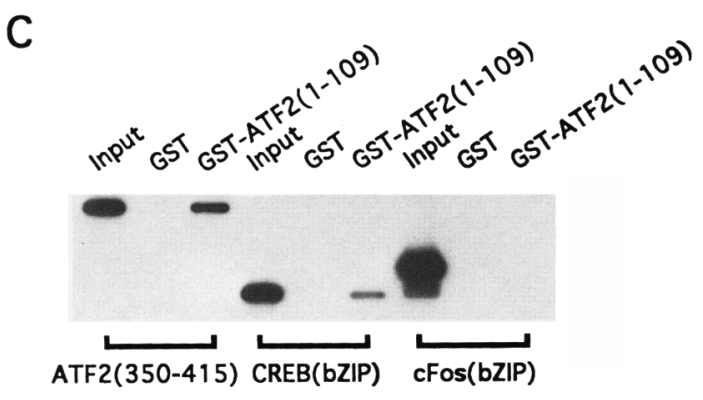

ATF-2 is constitutively active, whereas GAL4-ATF2(N,bZIP), in which the bZIP is fused directly to its carboxyl terminus, is not. These data suggest that a sequence between the activation domain and the bZIP is important for counteracting inhibition. Such a sequence could function merely to increase spacing between these two domains or have a more active role. To distinguish between these possibilities, we tested whether the relative position of the bZIP and activation domain affected inhibition. In the first set of experiments, we analyzed a fusion protein, GAL4-ATF-2(bZIP,N), in which the
ATF-2 activation domain was transferred to the carboxyl terminus. Figure 9A shows that GAL4-ATF-2(bZIP,N) was inactive in both CCL64 and HeLa cells, indicating that inhibition by the bZIP is independent of its position relative to the activation domain. Next, we compared the activities of GAL4-ATF-2(bZIP,1-349) and GAL4ATF-2(1-415), which contain the same sequences but differ by the relative positions of the bZIP and activation domain. In GAL4-ATF-2(bZIP,1-349) the two domains are located close to each other, whereas in GAL4-ATF$2(1-415)$ they are separated by residues $110-349$. The
GAL4 Fusion Derivatives

\section{Relative Activities}

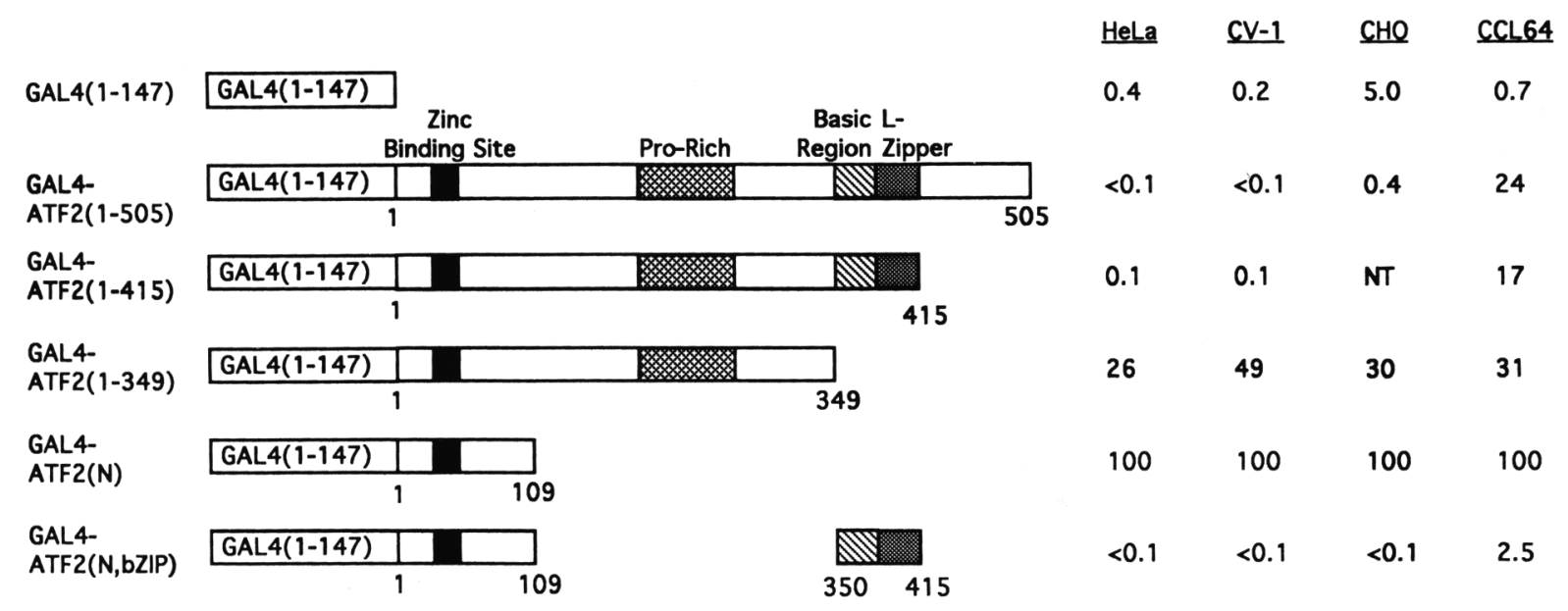

Figure 8. Cell-type specificity of bZIP-mediated inhibition. Relative transcriptional activities in different cells normalized to the activity of GAL4-ATF-2(N) are indicated together with diagrams for the GAL4 fusion proteins. (NT) Not tested. 
A
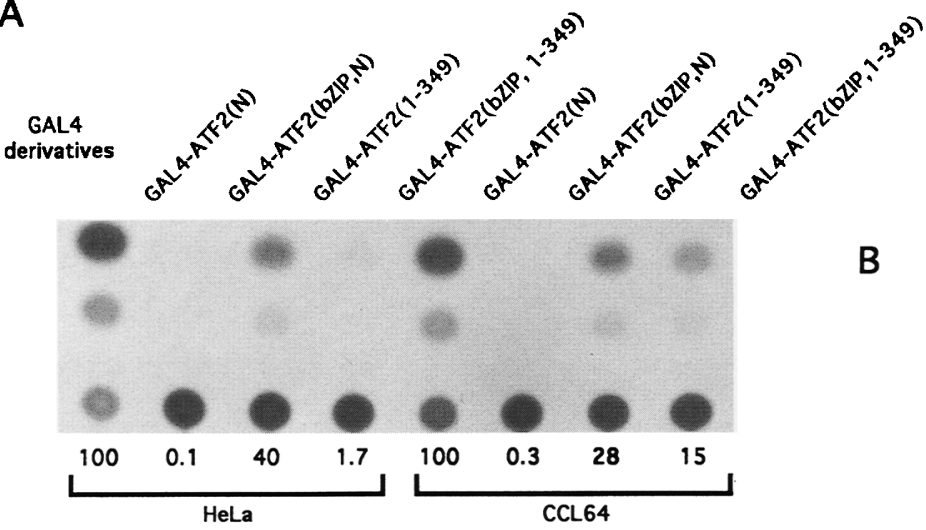

B

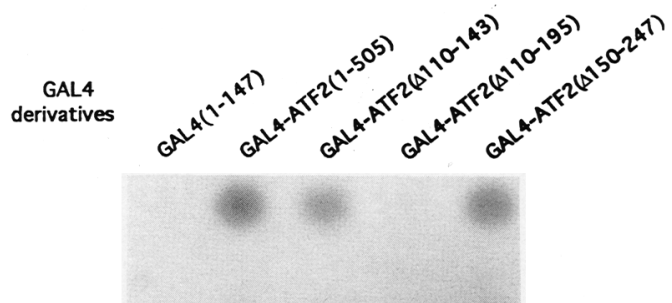

GAL4-ATF

(N)

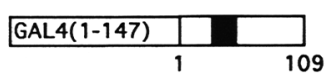

(bZIP,N)

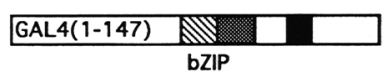

GAL4-ATF2

$(1-349)$

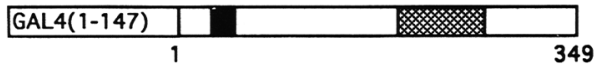

GAL4-ATF2 (bZIP, 1-349)
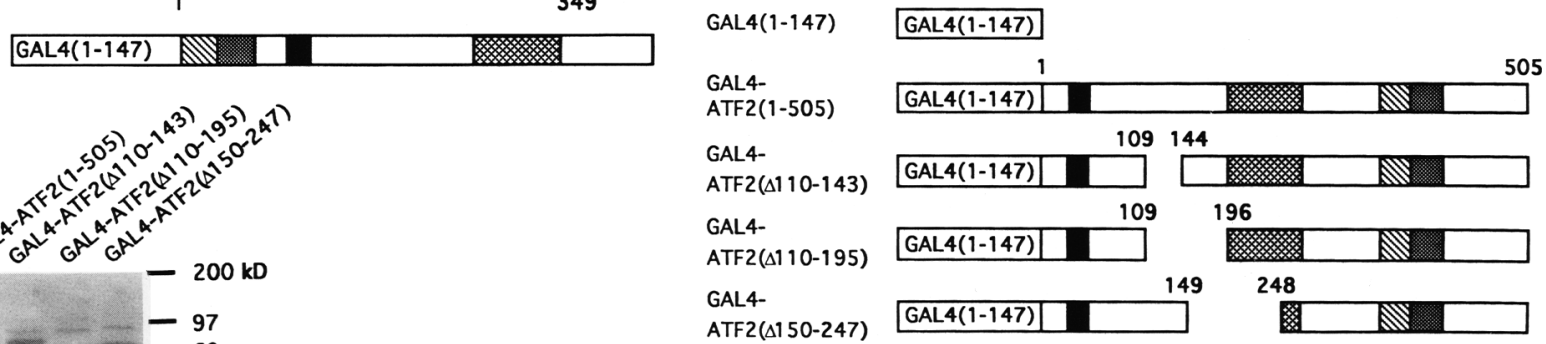

C

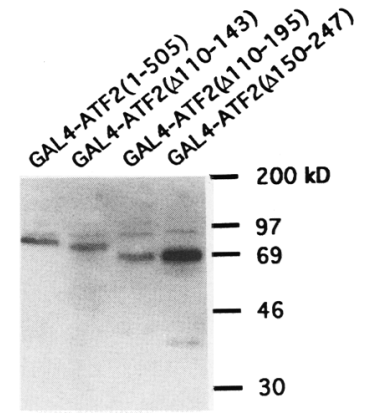

Figure 9. A specific ATF-2 sequence is responsible for cell-type-specific regulation (see Fig. 1 legend). (A) The role of ATF-2 sequences 110-349 in cell-type-specific activity. The cell type transfected is indicated below the autoradiograph. $(B)$ Delineation of the ATF-2 sequence responsible for activity in CCL64 cells. (C) Immunoblot analysis (as in Fig. 6). results of Figure 9A show that both proteins were active in CCL64 but not HeLa cells, indicating that ATF-2 sequences 110-349 can modulate bZIP-mediated inhibition in a position-independent manner.

To delineate further the sequence element responsible for counteracting inhibition, we constructed a series of internal deletion mutants and tested their activity in CCL64 cells. Figure 9B shows that deletion of residues 110-143, or residues 150-247, did not significantly affect activity, whereas deletion of residues 110-195 strongly reduced transcription. Figure 9C shows that the GAL4 fusion proteins were expressed at comparable levels. Therefore, the transcriptional activity of ATF- 2 in CCL64 cells can be attributed to a short sequence (residues 110-195) that counteracts bZIP-mediated inhibition in a cell-type-specific manner.

\section{Discussion}

A central question in the eukaryotic transcription field is how are promoter-specific transcription factors regu- lated? Several mechanisms by which activators are silenced in the absence of their inducers have been described and include, for example, sequestration in the cytoplasm (Picard and Yamamoto 1987; Baeuerle and Baltimore 1988; Beg and Baldwin 1993; Whiteside and Goodbourn 1993); interaction with inhibitory proteins (Moman et al. 1992; Helin and Harlow 1993); conformational inactivity (Morimoto 1993); and underphosphorylation (Karin and Hunter 1995). The collective results of this study reveal a new mechanism for rendering a transcription factor inactive, which involves a direct, intramolecular interaction between the activation domain and the DNA-binding domain. The data supporting this model, and the implications for activation, are discussed below.

Communication between the ATF-2 activation domain and $b Z I P$

A direct interaction between the ATF-2 activation domain and bZIP is suggested by the results of both in vitro 
and in vivo experiments. In an in vitro protein affinitychromatography assay, the ATF-2 activation domain specifically bound to its own bZIP. The functional significance of this in vitro interaction is supported by transfection experiments. The ATF-2 and Ela activation domains were strongly inhibited by the ATF- 2 bZIP in vivo, whereas the VP16 activation domain and the glutamine-rich activation domain A of Spl were not. Accordingly, the Ela (Liu and Green 1994; Livingstone et al. 1995) and the ATF-2 activation domain (this study), but not the VP16 activation domain, interact with bZIP in vitro. The CREB bZIP both inhibited and interacted with the ATF-2 activation domain (also see Abdel-Hafiz et al. 1992a). In contrast, the c-Fos bZIP neither inhibited nor interacted with the ATF2 activation domain.

Complementary to our results is the previous demonstration that the activation domain of ATF-2 strongly inhibits its ability to bind DNA in vitro (Abdel-Hafiz et al. 1992b|. Taken together, these observations suggest that the ATF- 2 activation domain and bZIP antagonize each other's function.

We note that both the ATF-2 and Ela activation domains, which interact with the ATF-2 bZIP, contain metal binding sites (Culp et al. 1988; Zu et al. 1991; Chatton et al. 1993). It is intriguing that several other protein-protein interactions appear to also involve a bZIP domain-metal binding site contact (Diamond et al. 1990; Jonat et al. 1990; Semmes and Jeang 1992; Wagner and Green 1993).

\section{Activation of ATF-2}

ATF- 2 can be activated by both regulatory proteins and through phosphorylation. Our results may be relevant to both of these activation mechanisms. Protein activators of ATF-2 include adenovirus Ela, HTLV-I Tax, and HMG $\mathrm{I}(\mathrm{Y})$. Significantly, each of these protein activators has been shown to interact with the ATF-2 bZIP (Du et al. 1993; Franklin et al. 1993; Wagner and Green 1993; Liu and Green 1994). These observations suggest a model in which binding of these regulatory proteins to the ATF-2 bZIP disrupts the intramolecular activation domainbZIP interaction leading to activation.

A second ATF-2 activation mechanism involves phosphorylation. Several studies have shown that the activation domain of ATF-2 can be phosphorylated by stressactivated protein kinases (SAPKs) (Gupta et al. 1995; Livingstone et al. 1995; van Dam et al. 1995), including INK, the c-Iun amino (N)-terminal protein kinase. An attractive idea is that phosphorylation disrupts the activation domain-bZIP interaction. Consistent with this possibility, phosphorylation of ATF-2 by MAP kinase dramatically increases its in vitro DNA-binding activity (Abdel-Hafiz et al. 1992b).

\section{Coordinate regulation of DNA-binding and activation domains}

An important implication of our model is that the ATF-2 activation domain and DNA-binding domain are coordi- nately regulated. We suggest that such coordinate regulation may be critical for activator function and proper transcriptional regulation. First, the ability of the DNAbinding domain to suppress the activation domain when not bound to DNA would help prevent the "squelching" of general transcription factors (or coactivators) (Ptashne 1988; Johansen and Prywes 1993). Second, coordinate regulation may also be important for function of a transcription factor family whose members have similar DNA-binding specificity. For example, the ATF/CREB factor family comprises more than a dozen proteins with virtually identical DNA-binding specificities (Hoeffler et al. 1988; Gonzalez et al. 1989; Hai et al. 1989; Maekawa et al. 1989; Gaire et al. 1990; Yoshimura et al. 1990; Foulkes et al. 1991) but whose responses to various inducing agents differ significantly (Gonzalez and Montminy 1989; Liu and Green 1990; Abdel-Hafiz et al. 1992). ATF/CREB proteins not involved in a particular transcriptional response may need to be prevented from binding to DNA to avoid blocking binding of the relevant ATF/CREB protein. Coordinate regulation of the DNA-binding and activation domain would help ensure that a factor binds to DNA only in the presence of its inducer.

Our results with ATF-2 may be applicable to other activators. For example, for several other promoter-specific transcription factors, the DNA-binding domain, or the act of DNA binding, appears to modulate the activation domain (Fujita et al. 1992; Johansen and Prywes 1993; Hill et al. 1994; Lefstin et al. 1994). Whether this is attributable to direct interaction between the DNA binding and activation domains, as with ATF-2, remains to be determined.

\section{Materials and methods}

Plasmids

pSGATF-2 (Liu and Green 1990) and pSGATF-2(N) (segment N corresponding to residues 1-109) (Liu and Green 1994) have been previously described. pSGATF-2(1-243), pSGATF-2(1349), pSGATF-2(1-380), pSGATF-2(1-415) contain the appropriate DNA fragments encoding residues $1-243,1-349,1-380$, or $1-415$ of ATF-2 inserted in-frame to the GAL4(1-147) sequence in the pSG424 vector (Sadowski and Ptashne 1989).

To generate pSGATF-2(1-349)-bZIPs [pSGATF-2(1-349)-Jun(bZIP), etc.), the DNA fragments encoding the bZIPs of CREB (residues 280-314) from rat, c-Jun (residues 248-340), c-Fos (residues 134-200) from mouse, and c/EBP (residues 278-357) from rat were amplified by PCR; the resulting PCR products were then inserted in-frame to the GAL4(1-147)-ATF-2(1-349) sequence in pSGATF-2(1-349). To create pSGATF-2(N)-CREB(bZIP), pSGATF-2(N)-CREB(bZIPm), pSGATF-2(N,bZIP), and pSGATF-2(N,LZ), the PCR-amplified DNA fragments encoding the CREB bZIP (residues 280-314), the CREB bZIP mutant containing a point mutation at position 304 (K304E) (Dwarki et al. 1990), the ATF-2 bZIP (residues 350-415), and the LZ of ATF-2 (375-415) were, respectively, inserted in-frame to the GAL4(1147)-ATF-2(N) sequence in pSGATF-2(N). pSGATF-2(bZIP,N) and pSGATF-2(bZIP, 1-349) were created by inserting the DNA fragment encoding ATF-2 bZIP into the junction between the GAL4(1-147) sequence and the ATF-2 activation domain se- 
quence in pSGATF-2(N) or residue 1-349 of ATF-2 in pSGATF2(1-349).

pSGVP16 contains the DNA fragment encompassing the activation domain (residues 414-490) of the herpes simplex virion protein VPl6 (Triezenberg et al. 1988) inserted in-frame to the GAL4(1-147) sequence in the pSG424 vector. pSGVP16-ATF2(bZIP) was derived by ligating the DNA fragment encoding ATF-2 bZIP to the GAL4(1-147)-VP16 sequence in pSGVP16. pCGSpl(Q) has been described (Southgate and Green 1995). pCGSpl(Q)-ATF-2(bZIP) was constructed by inserting the DNA fragment of the ATF-2 bZIP to the GAL4(1-95)-Spl|Q) sequence in pCGSp1(Q). To construct pGAL4-E1a(CR3)-ATF2 (bZIP), the DNA fragment of ATF-2 bZIP was inserted in-frame downstream of the GAL4(1-147)-E1a(121-223) sequence in pSG147-E1a (Lillie and Green 1989).

To construct pSGATF-2(A110-143), the AccI-BamHI fragment of ATF-2 (144-505) was inserted into the SacI site of pSG424 by blunt-end ligation; the EcoRI-BamHI fragment from the resulting plasmid was inserted into the $\mathrm{XbaI}$ site of $\mathrm{pS}$ GATF-2(N) by blunt-end ligation. To construct pSGATF2(A110-195), the ScaI-BamHI fragment of ATF-2 (196-505) was inserted into the BamHI site of the pSG 424 plasmid by bluntend ligation; the EcoRI fragment from the resulting plasmid was then inserted into the $X b a I$ site of the pSGATF-2(N) by bluntend ligation. pSGATF-2(D150-247) is a GAL4 fusion of CRE$\mathrm{BP} 2$, an isoform of ATF-2 that lacks residues 150-247 of fulllength ATF-2 as a result of alternative pre-mRNA splicing (Georgopoulos et al. 1992).

The reporter plasmid used in all of the transient transfection assays is pG5ElbCAT (Lillie and Green 1989), which contains five copies of the GAL4 DNA-binding site upstream of adenovirus Elb TATA element and the chloramphenicol acetyltransferase (CAT) gene.

The plasmids used for protein expression in Escherichia coli, including pGEX2T (Smith and Johnson 1988), pGVP (Lin and Green 1991), pGEX-ATF-2(1-349) (Liu and Green 1994), pGEXATF-2(1-109) (Liu and Green 1994), and pRsetB-ATF-2(350505) (Wagner and Green 1993) have been described previously. pRsetC-CREB(bZIP) and pRsetC-cFos(bZIP) were constructed by inserting the DNA fragments encoding the respective bZIP sequences to the $6 \mathrm{His}-\mathrm{T} 7$ tag sequence in pRsetC vector (Invitrogen).

\section{Cell culture and transfection}

HeLa, monkey kidney CV-1, mink lung CCL64, and COS- 1 cells were grown in Dulbecco's modified Eagle medium supplemented with $10 \%$ fetal bovine serum (FBS). The cells were split $1: 8$ (for HeLa and CV-1 cells), 1:16 (for CCL64 cells), or 1:7 (for COS-1 cells) $\sim 20 \mathrm{hr}$ prior to transfection by the calcium-phosphate transfection technique (Wigler et al. 1978). Each transfection mixture for HeLa, CV-1, and CCL64 cells contained $2 \mu \mathrm{g}$ of reporter plasmid, pG5E1bCAT, $2 \mu \mathrm{g}$ of plasmid encoding one of the GAL4 fusion proteins, as well as $3 \mu \mathrm{g}$ of RSV- $\beta$-gal plasmid as internal control. In all cases, the total amount of DNA for each transfection was adjusted to $20 \mu \mathrm{g}$ with pGEM3 (Promega). The cells were exposed to the precipitate for $\sim 20 \mathrm{hr}$. After washing, the cells were grown further for $36 \mathrm{hr}$ before being harvested.

CHO cells were grown in $\alpha$ minimal essential medium with nucleotides supplemented with $10 \%$ FBS. The cells were split 1:8 $24 \mathrm{hr}$ before transfection. DNA was introduced into the cells by the DEAE-dextran procedure (Wigler et al. 1978). Fourteen hours post-transfection cells were treated with dimethylsulfoxide (DMSO), followed by a treatment with choloroquine for 2.5 hr. The cells were harvested $48 \mathrm{hr}$ after the DMSO shock.
Cell extracts from the transfected cells were assayed for $\beta$-galactosidase activity and CAT activity as described (Sambrook et al. 1989). For CAT assays, the amount of cell extract used for each reaction was normalized by the $\beta$-galactosidase activity. All of the transfection experiments were repeated at least twice, the autoradiographs from the CAT assays presented are representative of each type of experiment, and the CAT activities shown are the average values from each type of experiment.

To analyze the expression of GAL4 fusion proteins, cell extracts prepared from transiently transfected COS-1 cells were fractionated by SDS-PAGE. GAL4 fusion proteins were detected by immunoblotting with a polyclonal GAL4(DBD) antibody (Santa Cruz Biotech., Inc.) using ECL (Amersham).

\section{Protein-affinity chromatography}

His-ATF-2(350-505), 6His-CREB(bZIP), and 6His-c-Fos(bZIP) were expressed and purified from $E$. coli using plasmids pRsetBATF-2(350-505), pRsetC-CREB(bZIP), and pRsetC-c-Fos(bZIP) as described previously (Wagner and Green 1993). GST, GSTVP16, GST-ATF-2(1-349), and GST-ATF-2(1-109) were expressed and purified from $E$. coli as described previously (Lin and Green 1991), with the following modifications. The E. coli lysate was prepared with buffer $\mathrm{A}[20 \mathrm{~mm}$ Tris- $\mathrm{HCl}$ at $\mathrm{pH} 8.0$, $1.0 \mathrm{M} \mathrm{NaCl}, 20 \mu \mathrm{M} \mathrm{ZnCl}, 5 \mathrm{mM} \beta$-mercaptoethanol, $0.5 \mathrm{~mm}$ phenylmethylsulfonyl fluoride [PMSF)] containing $\mathrm{l} \mu \mathrm{g} / \mathrm{ml}$ of pepstatin $\mathrm{A}$, and $1 \mu \mathrm{g} / \mathrm{ml}$ of leupeptin. After incubation of preswollen glutathione-agarose beads with precleared E. coli lysate, the beads were washed extensively, first with buffer A and then with buffer B [20 mM HEPES (pH 8.0), $0.1 \mathrm{M} \mathrm{KCl}, 20 \mu \mathrm{M}$ $\mathrm{ZnCl}_{2}, 10 \%$ glycerol, $5 \mathrm{~mm} \beta$-mercaptoethanol, $0.5 \mathrm{~mm}$ PMSF]. The proteins on the beads were eluted with $40 \mathrm{~mm}$ glutathione in buffer $\mathrm{B}$ that contained $150 \mathrm{mM}$ HEPES $(\mathrm{pH} 8.0\}$ and were dialyzed extensively against buffer $B$.

For protein-affinity chromatography, the purified GST or GST fusion proteins were recoupled to glutathione-agarose beads. Twenty microliters of the resulting beads containing equal amounts $(5 \mu \mathrm{g})$ of GST or one of the GST fusion proteins was incubated with $1.0 \mu \mathrm{g}$ of 6His-ATF-2(350-505), 6His-CREB(bZIP), or 6His-c-Fos(bZIP) in $0.6 \mathrm{ml}$ of the protein-binding buffer (10 mM HEPES at pH 8.0, $50 \mathrm{~mm} \mathrm{KCl,} 2.5 \mathrm{mM} \mathrm{MgCl}_{2}, 50$ $\mu \mathrm{M} \mathrm{ZnCl}, 0.025 \%$ NP-40, 0.5 mM DTT, 0.5 mM PMSF/ containing $60 \mu \mathrm{g}$ of bovine serum albumin. After incubating at $4^{\circ} \mathrm{C}$ for $2 \mathrm{hr}$ with continuous mixing, the beads were washed four times with $1 \mathrm{ml}$ of the protein-binding buffer over a period of $1 \mathrm{hr}$. 6His-ATF-2(350-505), 6His-CREB(bZIP), and 6His-c-Fos(bZIP) bound to the beads were eluted by SDS sample buffer, fractionated by SDS-PAGE, and detected by immunobloting with a monoclonal T7-Tag antibody (Novagen).

\section{Acknowledgments}

We thank F. Liu and W. Du for plasmids; and F. Liu, J. Valcarcel, S. Roberts, S. Wagner, J. Reese, G. Perini, and other members of the Green laboratory for critical reading of the manuscript and helpful discussions. M.R.G. is an investigator for the Howard Hughes Medical Institute. This work was supported by a grant from the National Institutes of Health to M.R.G.

The publication costs of this article were defrayed in part by payment of page charges. This article must therefore be hereby marked "advertisement" in accordance with 18 USC section 1734 solely to indicate this fact.

\section{References}

Abdel-Hafiz, H.A.-M., C.-y. Chen, T. Marcell, D.J. Kroll, and J.P. 
Hoeffler. 1992a. Structural determinants outside of the leucine zipper influence the interactions of CREB and ATF-2: Interaction of CREB with ATF-2 blocks Ela-ATF-2 complex formation. Oncogene 8: 1161-1174.

Abdel-Hafiz, H.A.-M., L.E. Heasley, J.M. Kyriakis, J. Avruch, D.J. Kroll, G.L. Johnson, and J.P. Hoeffler. 1992b. Activating transcription factor-2 DNA-binding activity is stimulated by phosphorylation catalyzed by $\mathrm{p} 42$ and p 54 microtubule-associated protein kinase. Mol. Endocrinol. 6: 20792089.

Baeuerle, P.A. and D. Baltimore. 1988. ІкB: A specific inhibitor of the NF-кB transcription factor. Science 242: 540-546.

Baichwal, V.R. and R. Tjian. 1990. Control of c-Jun activity by interaction of a cell-specific inhibitor with regulatory domain $\delta$ : Differences between $\mathrm{v}$ - and c-Jun. Cell 63: $815-825$.

Beg, A.A. and A.S.J. Baldwin. 1993. The IкB proteins: Multifunctional regulators of Rel/NF- $\mathrm{B}$ transcription factors. Genes \& Dev. 7: 2064-2070.

Chatton, B., J.L. Bocco, M. Gaire, C. Hauss, B. Reimund, J.Goetz, and C. Kdinger. 1993. Transcriptional activation by the adenovirus large Ela product is mediated by members of the cellular transcription factor ATF family which can directly associate with Ela. Mol. Cell. Biol. 13: 561-570.

Courey, A. and R. Tjian. 1988. Analysis of Spl in vivo reveals multiple transcriptional domains, including a novel glutamine-rich activation motif. Cell 55: 887-898.

Culp, J.S., L.C. Webster, D.J. Friedman, C.L. Smith, W.J. Huang, F. Y.-H. Wu, M. Rosenberg, and R.P. Ricciardi. 1988. The 289-amino acid Ela protein of adenovirus binds zinc in a region that is important for trans-activation. Proc. Natl. Acad. Sci. 89: 2150-2154.

Diamond, M.I., J.N. Miner, S.K. Yoshinaga, and K.R. Yamamoto. 1990. Transcription factor interactions: selectors of positive or negative regulation from a single DNA element. Science 249: 1266-1272.

Du, W., D. Thanos, and T. Maniatis. 1993. Mechanisms of transcriptional synergism between distinct virus-inducible enhancer elements. Cell 74: 887-898.

Dwarki, V.J., M. Montminy, and I.M. Verma. 1990. Both the basic region and the "leucine zipper" domain of the cyclic AMP response element binding (CREB) protein are essential for transcriptional activation. EMBO I. 9: 225-232.

Evans, R. 1988. The steroid and thyroid hormone receptor superfamily. Science 240: 889-895.

Flint, J. and T. Shenk. 1989. Adenovirus Ela protein paradigm viral transactivator. Annu. Rev. Genet. 23: 141-161.

Foulkes, N.S., E. Borrelli, and P. Sassone-Corsi. 1991. CREM gene, use of alternative DNA-binding domains generates multiple antagonists of cAMP-induced transcription. Cell 64: 739-749.

Franklin, A.A., M.K. Kubik, M.N. Uittenbogaard, A. Brauweiler, P. Utaisincharoen, M.-A.H. Matthews, W.S. Dynan, J.P. Hoeffler, and J.K. Nyborg. 1993. Transactivation by the human T-cell leukemia virus Tax protein is mediated through enhanced binding of activating transcription factor-2 (ATF2) ATF2 response and cAMP element-binding protein (CREB). I. Biol. Chem. 268: 21225-21231.

Fujita, T., G.P. Nolan, S. Ghosh, and D. Baltimore. 1992. Independent modes of transcriptional activation by the p50 and p65 subunits of NF-кB. Genes \& Dev. 6: 775-787.

Gaire, M., B. Chatton, and C. Kedinger. 1990. Isolation and characterization of two novel, closely related ATF cDNA clones from HeLa cells. Nucleic Acids Res. 18: 3467-3473.

Georgopoulos, K., B.A. Morgan, and D.D. Moore. 1992. Functionally distinct isoforms of the CRE-BP DNA-binding pro- tein mediate activity of a T-cell-specific enhancer. Mol. Cell. Biol. 12: 747-757.

Gonzalez, G.A. and M. Montminy. 1989. Cyclic AMP stimulates somatostatin gene transcription by phosphorylation of CREB at serine 133. Cell 59: 675-680.

Gonzalez, G.A., K.K. Yamamoto, W.H. Fischer, D. Karr, P. Menzel, W.I. Biggs, W.W. Vale, and M. Montminy. 1989. A cluster of phosphorylation sites on the cyclic AMP-regulated nuclear factor CREB predicted by its sequence. Nature 337: 749-752.

Gupta, S., D. Campbell, B. Derijard, and R.J. Davis. 1995. Transcription factor ATF2 regulation by the JNK signal transduction pathway. Science 267: 389-393.

Hai, T., F. Liu, W.J. Coukos, and M.R. Green. 1989. Transcription factor ATF cDNA clones: An extensive family of leucine zipper proteins able to selectively form DNA-binding heterodimers. Genes \& Dev. 3: 2083-2090.

Helin, K. and E. Harlow. 1993. The retinoblastoma protein as a transcriptional repressor. Trends Cell Biol. 3: 43-46.

Hill, C.S., J. Wynne, and R. Treisman. 1994. Serum-regulated transcription by serum response factor (SRF): A novel role for the DNA binding domain. EMBO /. 13: 5421-5432.

Hoeffler, J.P., T.E. Meyer, Y. Yun, J.L. Jameson, and J.F. Habener. 1988. Cyclic-AMP-responsive DNA-binding protein: Structure based on a cloned placental cDNA. Science 242: 1430-1433.

Ivashkiv, L.B., M.D. Fleming, and L.H. Glimcher. 1992. Dominant negative mutants of transcription factor $\mathrm{mXBP}$ (CREBP1, ATF2). New Biol. 4: 360-368.

Johansen, F.-E. and R. Prywes. 1993. Identification of transcriptional activation and inhibitory domains in serum response factor (SRF) by using GAL4-SRF constructs. Mol. Cell. Biol. 13: $4640-4647$.

Johnson, P.F. and S.L. McKnight. 1989. Eukaryotic transcriptional regulatory proteins. Annu. Rev. Biochem. 58: 799-839.

Jonat, C., H.J. Rahmsdorf, K.-K. Park, A.C.B. Cato, S. Gebel, H. Ponta, and P. Herrlich. 1990. Antitumor promotion and antiinflammation: down-modulation of AP-1 (Fos/Jun) activity by glutocorticoid hormone. Cell 62: 1189-1204.

Karin, M. and T. Hunter. 1995. Transcriptional control by protein phosphorylation: signal transmission from the cell surface to the nucleus. Curr. Biol. 5: 747-757.

Kim, S.-J., S. Wagner, F. Liu, M.A. O'Reilly, P.D. Robbins, and M.R. Green. 1992. Retinoblastoma gene product activates expression of the human TGF- $\beta 2$ gene through transcription factor ATF2. Nature 358: 331-334.

Lefstin, J. A., J.R. Thomas, and K.R. Yamamoto. 1994. Influence of a steriod receptor DNA-binding domain on transcriptional regulatory functions. Genes \& Dev. 8: 2842-2856.

Lillie, J.W. and M.R. Green. 1989. Transcriptional activation by the adenovirus Ela protein. Nature 338: $39-44$.

Lin, Y.-S. and M.R. Green. 1991. Mechanism of activation of an acidic transcriptional activator in vitro. Cell 64: 971-981.

Liu, F. and M.R. Green. 1990. A specific member of the ATF transcription factor family can mediate transcription activation by the adenovirus E1a protein. Cell 67: 1217-1224.

- 1994. Promoter targeting by adenovirus Ela through interaction with different cellular DNA-binding domains. $\mathrm{Na}$ ture 368: 520-525.

Livingstone, C., G. Patel, and N. Jones. 1995. ATF-2 contains a phosphorylation-dependent transcriptional activation domain. EMBO I. 14: 1785-1797.

Maekawa, T., S. Matsuda, J.I. Fujisawa, M. Yoshida, and S. Ishii. 1989. Leucine zipper structure of the protein CRE-BP1 binding to the cyclic-AMP responsive element in brain. EMBO $\%$. 8: 2023-2028. 
Maekawa, T., S. Matsuda, J.I. Fuijsawa, M. Yoshida, and S. Ishii. 1991. Cyclic-AMP-response element binding protein, CRE$\mathrm{BPl}$, mediates the Ela-induced but not the Tax-induced trans-activation. Oncogene 6: 627-632.

Maguire, H.F., J.P. Hoeffler, and A. Siddiqui. 1991. HBV X protein alters the DNA binding specificity of CREB and ATF-2 by protein-protein interactions. Science 252: 842-844.

Martin, K. and M.R. Green. 1992. Transcriptional activation by viral immediate-early proteins: variations on a common theme. In Transcriptional regulation (ed. S.L. McKnight and K.R. Yamamotol, pp. 695-725. Cold Spring Harbor Laboratory Press, Cold Spring Harbor, NY.

Moman, J., G.P. Zambetti, D.C. Olson, D. George, and A. Levine. 1992. The mdm-2 oncogene product forms a complex with the p53 protein and inhibits p53-mediated transactivation. Cell 69: 1237-1245.

Morimoto, R. 1993. Cells in stress: transcriptional activation of heat shock genes. Science 259: 1409-1410.

O'Hare, P. 1993. The virion transactivator of herpes simplex virus. In The alpha-herpesviruses (ed. A.J. Davison), pp. 145155. Saunders Scientific Publications, Philadelphia, PA.

O'Shea, E.K., R. Rutkowski, W.F. Stafford III, and P.S. Kim. 1989. Preferential heterodimer formation by isolated leucine zippers from Fos and Jun. Science 254: 539-544.

Picard, D. and K.R. Yamamoto. 1987. Two signals mediate hormone-dependent nuclear localization of the glucocorticoid receptor. EMBO J. 6: 3333-3340.

Ptashne M. 1988. How eukaryotic transcriptional activators work. Nature 335: 683-689.

Sadowski, I. and M. Ptashne. 1989. A vector for expressing GAL4(1-147) fusion in mamaliam cells. Nucleic Acids Res. 17: 7539 .

Sambrook, J., E.F. Fritsch, and T. Maniatis. 1989. Molecular cloning: A laboratory manual. Cold Spring Harbor Laboratory Press, Cold Spring Harbor, NY.

Semmes, O.J. and K.-T. Jeang. 1992. HTLV-I Tax is a zinc binding protein: Role for zinc in Tax structure and function. Virology 188: 754-764.

Smith, D.B. and K.S. Johnson. 1988. Single-step purification of polypeptides expressed in Escherichia coli as fusions with glutathione S-transferase. Gene 67: 31-40.

Southgate, C.D. and M.R. Green. 1995. Delineating minimal protein domains and promoter elements for transcriptional activation by lentivirus Tat proteins. J. Virol. 69: 2605-2610.

Thompson, C.C. and S.L. McKnight. 1992. Anatomy of an enhancer. Trends Genet. 8: 232-236.

Triezenberg, S.J. 1995. Structure and function of transcriptional activation domains. Curr. Opin. Genet. Dev. 5: 190-196.

Triezenberg S.J., R.C. Kingsbury, and S.L. McKnight. 1988. Functional dissection of VP16, the trans-activator of herpes simplex virus immediate early gene expression. Genes \& Dev. 2: 718-729.

van Dam, H., D. Wilhelm, I. Herr, A. Steffen, P. Herrlich, and P. Angel. 1995. ATF-2 is preferentially activated by stress-activated protein kinases to mediate c-jun induction in response to genotoxic agents. EMBO I. 14: 1798-1811.

Wagner, S. and M.R. Green. 1993. HTLV-1 Tax protein stimulation of DNA binding of bZIP proteins by enhancing dimerization. Science 262: 395-399.

Walker, S., S. Hayes, and P. O'Hare. 1994. Site-specific conformational alteration of the Oct- 1 POU domain-DNA complex as the basis for differential recognition by Vmw65(VP16). Cell 79: 841-852.

Whiteside, S.T. and S. Goodbourn. 1993. Signal transduction and nuclear targeting: Regulation of transcription factor activity by subcellular localization. J. Cell Sci. 104: 949-955.
Wigler, M., A. Pellicer, S. Silverstein, and P. Axel. 1978. Biochemical transfer of single-copy eukaryotic genes using total cellular DNA as donor. Cell 14: 725-731.

Yoshimura, T., J.-I. Fujisawa, and M. Yoshida. 1990. Multiple cDNA clones encoding nuclear proteins that bind to the taxdependent enhancer of HTLV-1: All contain a leucine zipper structure and basic amino acid domain. EMBO /. 9: 25372542.

Zu, Y.-L. T. Maekawa, S. Matsuda, and S. Ishii. 1991. Complete putative metal finger and leucine zipper structures of CRE$\mathrm{BP} 1$ are required for the $\mathrm{E} 1 \mathrm{a}$-induced trans-activation. J. Biol. Chem. 266: 24134-24139. 


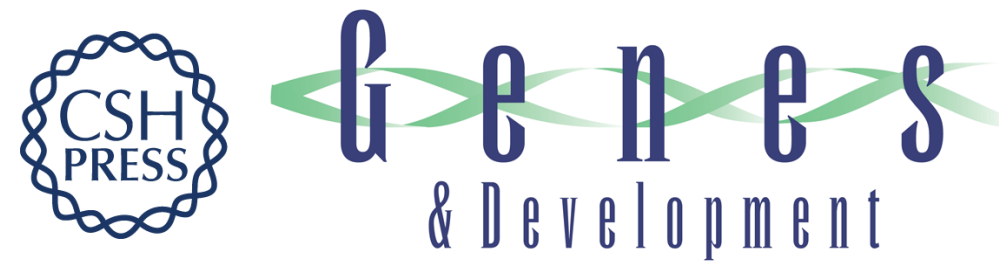

\section{Intramolecular inhibition of activating transcription factor-2 function by its DNA-binding domain.}

$X Y \mathrm{Li}$ and M R Green

Genes Dev. 1996, 10:

Access the most recent version at doi:10.1101/gad.10.5.517

References This article cites 59 articles, 20 of which can be accessed free at: http://genesdev.cshlp.org/content/10/5/517.full.html\#ref-list-1

License

Email Alerting

Service

Receive free email alerts when new articles cite this article - sign up in the box at the top right corner of the article or click here.

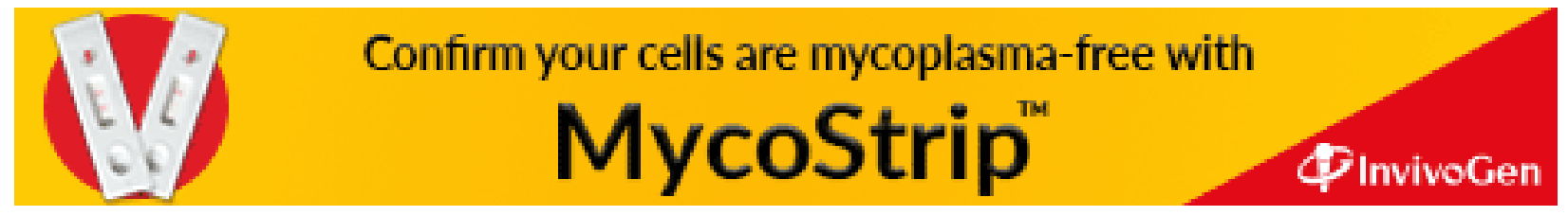

